\title{
WestVirginiaUniversity
}

THE RESEARCH REPOSITORY @ WVU

Graduate Theses, Dissertations, and Problem Reports

1999

\section{Explanatory models of chronic pain}

Elizabeth Neely Thrush

West Virginia University

Follow this and additional works at: https://researchrepository.wvu.edu/etd

\section{Recommended Citation}

Thrush, Elizabeth Neely, "Explanatory models of chronic pain" (1999). Graduate Theses, Dissertations, and Problem Reports. 1032.

https://researchrepository.wvu.edu/etd/1032

This Thesis is protected by copyright and/or related rights. It has been brought to you by the The Research Repository @ WVU with permission from the rights-holder(s). You are free to use this Thesis in any way that is permitted by the copyright and related rights legislation that applies to your use. For other uses you must obtain permission from the rights-holder(s) directly, unless additional rights are indicated by a Creative Commons license in the record and/ or on the work itself. This Thesis has been accepted for inclusion in WVU Graduate Theses, Dissertations, and Problem Reports collection by an authorized administrator of The Research Repository @ WVU. For more information, please contact researchrepository@mail.wvu.edu. 


\title{
EXPLANATORY MODELS OF CHRONIC PAIN
}

\author{
Elizabeth Neely Thrush
}

Thesis submitted to the School of Medicine

\author{
At West Virginia University \\ In partial fulfillment of the requirements \\ For the degree of \\ Masters of Science \\ In \\ Community Health Promotion \\ Irene Tessaro, Ph.D., Chair \\ Ruth Kershner, Ph.D. \\ William Reger, Ph.D.
Department of Community Medicine
Morgantown, West Virginia
1999 \\ Key Words: pain, chronic, fibromyalgia \\ Copyright 1999 Elizabeth Neely Thrush
}




\section{ABSTRACT \\ EXPLANATORY MODELS OF CHRONIC PAIN}

\section{Elizabeth Neely Thrush}

Chronic pain is described as pain that persists for six months or longer. This type of pain may range from dull to excruciating and may be constant or sporadic. The purpose of this study was to explore the explanatory models of individuals living in chronic pain. The study sample included twelve adults, eleven women and one man, who have been diagnosed with the chronic pain condition Fibromyalgia. Using Arthur Kleinman's explanatory models as a framework, participants were personally interviewed regarding the physical, personal, and social causes and consequences of chronic pain. In order to elicit personal explanatory models, each participant was encouraged to discuss any personally significant aspect of their chronic pain experience. Upon completion of the qualitative interviews, data was analyzed using a descriptive research method. The statistical analysis system NUDIST, a text analysis system for microcomputers, was used in order to organize the data. Results yielded three major explanatory themes. First, there was a general lack of understanding regarding the etiology and pathology of fibromyalgia. Secondly, the majority of participants expressed great frustration and/or anxiety in regards to pain etiology, the future, personal relationships, and treatment. Lastly, participants reported significantly decreased social interaction as an effect of living with chronic pain. This work is significant in that increased understanding of the chronic pain experience lends itself to positively impacting the negative aspects of this experience. 


\section{ACKNOWLEDGEMENTS}

I would like to thank the members of my thesis committee, Dr. Irene Tessaro, Dr. Ruth Kershner, and Dr. Bill Reger for both supporting and guiding me through this project.

I would also like to thank the members of the fibromyalgia support group without whom this research would not have been possible.

Lastly, and most importantly, I would like to thank my family and friends for their never ending encouragement. There is clarity in absurdity and beauty in pain. 


\section{TABLE OF CONTENTS}

I. Introduction 1

II. Background and Literature Review 4

A. Physiological Overview 4

B. Personal Effects $\quad \mathbf{1 0}$

C. Social Support $\quad 17$

D. Explanatory Models $\quad 22$

E. Conclusion $\quad 26$

III. Qualitative Methods 28

A. Sample $\quad 28$

B. Data Collection $\quad 29$

C. Data Analysis 30

IV. Results 31

A. Sample Characteristics $\quad 31$

B. Etiology $\quad 31$

C. Onset $\quad 34$

D. Pathophysiology $\quad 35$

E. Future Course $\quad 36$

F. Treatment $\quad \mathbf{4 0}$

G. Conclusion 4

V. Discussion 43

A. Major Findings $\quad 43$

B. Study Limitations

C. Implications and Future Research $\quad 46$

Appendices

A. Informed Consent $\quad 47$

B. Pain Intensity Scale $\quad 48$

References 


\section{EXPLANATORY MODELS OF CHRONIC PAIN \\ Introduction}

Chronic pain, and the experience of living with that pain, is uniquely individual. A person's perception of pain is affected by physical, psychological, and social factors (Miller \& Kraus, 1990). Physically, pain typically presents as a leading symptom of injury or illness. This type of short-lived acute pain is the body's natural response to correctly interpreted physiological data. However, in some cases, and often for unexplainable reasons, pain lingers long after expected recovery time. After a duration of approximately six months, this type of pain is labeled 'chronic.' The person living with chronic pain may see a multitude of physicians and may undergo a plethora of treatments. Nonetheless, the search for pain etiology often results in medical dismissal, meaning that a person may encounter doubt and/or lack of appropriate concern from the medical community. (Kleinman, 1988). The personal and social effects of this dismissal may become as complex as the pain itself.

Physical pain often translates into psychological pain (White, Lefort, Amsel, \& Jeans, 1997). Whatever the physiological symptoms, the chronic pain patient may feel like an individual trapped within the walls of a malfunctioning body. The emotional consequences of living in pain may include hopelessness, anxiety, fear, and depression (Wade, Prince, Hammer, Schwartz, \& Hart, 1990). Accordingly, it is theorized that depressed mood may result in a decreased level of pain tolerance (Weisenberg, Krendler,

Schachat \& Werboff, 1975). Thus, while pain may cause negative emotion, negative emotion may in turn perpetuate pain. The causal effect of each on the other is one of the foremost mysteries of the chronic pain experience. 
Living with chronic pain may affect social identity as well (Hendler, 1996). For example, persons in pain may no longer be able to participate in a number of their former social activities. One's social response to pain and, in turn, the response of a social network can largely impact the pain experience. Social support may be positive or negative in nature. Negative interactions may result as family and friends struggle with the way in which an individual's pain affects their lives. As frustration mounts, either the individual and/or the social group may withdraw. Conversely, positive social interaction can result in the emotional, informational, and instrumental support that a person needs in order to effectively cope with pain.

For the majority of chronic pain conditions, no completely successful treatment is known (Lister, 1996). Ultimately, it is possible that both interior and exterior perceptions are irrevocably altered as a result of living with this pain. What are these perceptions and how do they affect an individual's quality of life? The purpose of this study is to explore the emotional and social world of the individual living with chronic pain. Using a qualitative interview method, explorations into personal experience will include the areas of physical, psychological, and social health perceptions. Individual personal narratives/explanatory models will then be analyzed for group similarity. This work is significant in that increased understanding of the pain experience lends itself to improving the negative aspects of this experience. From a social science perspective, the issue becomes not how to medically treat these conditions but how to improve the quality of life among persons living with chronic pain. 


\section{Research Questions:}

(1) What are individuals' experiences with chronic pain?

(2) What are individuals' explanatory models regarding chronic pain?

(3) How does chronic pain affect a person's quality of life and social relationships? 


\section{I.}

\section{Defining Pain}

\section{Physiological Overview}

Although simplistic by definition, the term pain may be theoretically difficult to interpret. The experience of physical pain is defined as a sensation of hurt and discomfort in some part of the body. Biologically, pain occurs as a symptom of injury, disease, or a systematic/functional disorder. This pain typically ceases as a result of natural healing or medical intervention. Pain etiology and treatment, however, is not always straightforward. The interplay of factors leading to the development of pain, and chronic pain in particular, is a complex phenomenon. Miller and Kraus (1990) state that chronic pain can be "a syndrome with multiple etiologies operating simultaneously and changing over the course of an illness." Potential contributing elements may include neurologic, physiologic, psychological, sociocultural, motivational, cognitive, and behavioral components (Miller \& Kraus, 1990). Therefore, when assessing pain, it is necessary to acknowledge the relevance of multiple variables associated with each person's pain experience.

Pain can be separated into two categories, acute and chronic. Acute pain serves a biological function in that it prepares the body to cope with disease or injury, warns of malfunction, and prompts the individual to seek treatment. Acute pain has a defined beginning and end. Chronic pain, on the other hand, is defined as pain that persists for more than six months. Chronic pain does not have a definite beginning or end and may lie anywhere on a continuum from dull to excruciating. For the majority of chronic pain patients, physical signs of acute distress such as increased respiratory and heart rates or other observable physical symptoms are not present. 
Chronic pain is either benign or malignant by nature. Pain caused by malignancy is rooted in physical disease. Malignant conditions tend to infiltrate, metastasize, and produce deterioration or death. This group is organic in that physical findings are typically sufficient to account for level and duration of pain. The goal of treating malignant chronic pain is simply to minimize pain with limited side effects (Berry, 1992). Benign pain, on the other hand, is pain that does not threaten life. This type of pain can be more difficult to treat due to the fact that exact physiological origin is often unknown. While benign pain may be organic in nature, it may also be functional. Functional pain occurs when physical findings do not account for the patient's complaints. In treating functional pain, health care providers may fear the risk of secondary gain to the patient (Portnoy \& Kanner, 1996). Secondary gain may lead to effects such as drug addiction or psychological/social dependence. However, when there is a physiological need for analgesics, the majority of clinicians agree that addiction is not likely to occur.

\section{$\underline{\text { Pain Transmission }}$}

All pain messages travel to and from the brain via the spinal cord. Pain travels on an ascending tract as receptors transmit pain information from various bundles of nerve fibers to cells in the dorsal horn of the spinal cord and on to the brain. Acute pain is physiologically interpreted as "fast pain." Fast pain is felt as sharp or stabbing pressure that is immediately relayed in response to an injury or damage. For example, placing one's hand on a hot stove will immediately transmit pain signals through the spinal cord and into the thalamus and cortex, the section of the brain in which the majority of thought processes occur. Almost instantaneously, the cortex registers the pain message, causing a jerk reflex. This fast pain tract is called the neospinothalamic pathway. 
Conversely, chronic pain is physiologically interpreted as "slow pain." Slow pain may be interpreted as dull, aching, burning, or cramping. Like acute pain, chronic pain messages may travel to and from the brain on an ascending tract via the spinal cord. Slow pain messages, however, are transmitted to the thalamus and limbic structures on the paleosinothalamic pathway. While the thalamus controls the release of certain stress hormones via the pituitary gland, emotions are processed in the limbic structures. This paleosinothalamic pathway tract helps to explain the role of stress and emotion in the experience of chronic pain.

In some cases, pain is transmitted from the brain through the cells in the spinal cord and to various nerve bundles. This pathway is called the descending tract. In the descending pathway, neurotransmitters and nerve impulses are transmitted from the brain and are interpreted as pain. Neurotransmitters (e.g. serotonin) are the chemical substances that either relay a pain message or cause the cessation of that message. Therefore, they either produce pain or act as painkillers. Serotonin is one of the most important chemicals involved in pain cessation. Improper neurotransmitter levels or malfunctioning nerve impulses may individually or collectively exacerbate pain. The downward tract explanation accounts for the success of therapies such as biofeedback, cognitive restructuring, and brain stimulation in treating chronic pain. (Light, 1992)

There are four types of chronic pain: (Markenson, 1996)

(1) Pain persisting beyond the normal healing time for a disease or injury (e.g. chronic back pain).

(2) Pain related to chronic degenerative diseases or a persistent neurologic condition (e.g. rheumatoid arthritis, osteoarthritis, and neuralgia). 
(3) Pain that emerges or persists, possibly ranging from months to years, without an identifiable cause (e.g. fibromyalgia, vulvar vestibulitis, pelvic pain, chronic fatigue syndrome).

(3) Cancer pain - Pain associated with progressive medical disease and treatment.

\section{Pain Models \& Theories:}

\section{Sensory Model of Pain}

The sensory model of pain focuses on the body's response to sensory stimuli resulting from some type of physical damage. In this model, the impacts of tissue damage are transmitted from the damaged nerve endings or pain receptors through the peripheral A delta and $\mathrm{C}$ nerve fibers to the antheolateral sinothalmic tract. All nerve impulses are then conducted through the sinothalmic tract to the thalamus and higher brain centers resulting in the sensory experience of pain. This stimulus response concept is known as specificity theory. In short, specificity theory maintains that the intensity of pain is directly proportional to the amount of damage. (Arnoff, 1985)

\section{Gate Control Theory}

Melzac and Wall's Gate Control Theory maintains that there are "gates" on the spinal cord nerve fibers that either open and transmit pain impulses to the brain or close and cut off these impulses. Therefore, somatic input is subjected to the modulating gate influence before transmitting perception and response. Large fiber input tends to close the gate while small fiber input tends to open it, with gate modulation depending greatly on neurotransmission from the brain. A certain amount of stimuli can thusly close the gate to the pain sensation. Decreased pain results when the number of nerve impulses that arrive at these areas exceed a certain level. This theory helps to explain why 
therapies such as massage, acupuncture, and stimulators can often successfully reduce chronic pain. (Arnoff, 1985)

\section{Imprinting}

The sensory model and the gate control theory offer explanations for pain induced by stimulus-effect. However, they are ineffective in explaining the type of pain that continues after expected recovery time. The theory of imprinting attempts to explain why pain may persist after initial healing or without known origin. This theory maintains that the nervous system may become conditioned to transmit pain messages. The central nervous system may retain the memory of pain and may transmit this remembered pain to certain areas of the body long after there is a biological need for the pain. In part, imprinting may be viewed as a psychophysiologic theory in that it may be affected by a combination of pain impulses, neurotransmitters, emotions, and cognitive processes. (Catalano \& Hardin, 1996)

\section{Treatment Overview}

The negative psychological aspects of acute pain are normally minimal (Berry, 1992). However, chronic pain often results in long-term physical limitations coupled with psychological and social problems (Kantor, 1996). The treatment of chronic pain, especially that of an unspecified origin, can be a complex process. Both pharmacological and non-pharmacological measures, either alone or in combination, may successfully manage a chronic pain condition.

Pharmacological measures include non-steroid anti-inflammatory drugs (NSAID), non-NSAID over-the-counter analgesics (e.g. acetaminophen), and centrally acting analgesics (e.g. opiod agents). In addition, antidepressants and anticonvulsants may be 
administered. In some cases, due to the potential physical consequences of the long term of pharmacological measures, non-pharmacological modalities may provide better options. These measures include physical therapy, diet modification, transcutaneous nerve stimulation (TENS), relaxation techniques, biofeedback, acupuncture, massage, hypnosis, individual psychotherapy, group/family psychotherapy, and cognitivebehavioral restructuring.

Pain is a subjective experience. Therefore, no single treatment option, or combination of options, is right for every person. For the majority of chronic pain conditions, complete pain cessation is an unrealistic goal (Kantor, 1996). Therefore, in conjunction with medical advice, each individual must determine the most effective ways in which to both reduce and manage personal pain. 
II.

\section{Personal Effects}

The personal effects of living with chronic pain vary among individuals.

Researchers have long sought to determine the psychological factors that both contribute to and/or result as a consequence of the pain experience. Violon (1987) maintains that it is necessary to refer to psychological determinants in order to understand why some persons continue to experience pain after physical damage has healed. Systematic pain, (pain which signals alarm) is useful in that it is a symptom of physical disease. However, she argues that it is possible for this pain to become a disease in itself. This useless pain, termed alyopathia, may be a symptom of dysfunction at any level of the nervous system (Violon, 1982). Thus, it can be argued that psychological dysfunction may preempt a psychogenic pain experience. Alternatively, negative psychological consequences may arise as a consequence of physical pain. Persons who might otherwise effectively cope with physical and emotional setbacks may experience emotional unpleasantness and excessive suffering as a result of uncontrollable pain (Chapman \& Gavrin, 1999).

No single emotion, or group of emotions, has been found to be a definitive precursor to or consequence of pain. In a study seeking to determine the contributions of varying psychological states to the unpleasantness and depression that pain patients experience, Wade, Price, Hammer, Sckwartz, \& Hart (1990) conclude that pain may be accompanied by a variety of disturbing emotions. Depending on a variety of circumstances, these emotions may include anxiety, frustration, anger, fear, or depression

(Wade, Price, Hammer, Schwartz, \& Hart, 1990). Similarly, in an overview of chronic pain, Miller and Krause (1990) conclude that pain may manifest itself as emotional 
distress and may result from anxiety, stress or tension. This manifestation may be multidimensional, affecting pain intensity, pain location, physical state, psychological state, and inferred meaning of pain (Weisenberg et al., 1975).

\section{Personality}

In the literature regarding chronic pain, questions arise as to whether certain personality traits might contribute to the likelihood of experiencing this type of pain. The early work of Freud (1917) suggests that physical pain may result as a consequence of unresolved subconscious emotion. Thus, pain may manifest if a conflict is perceived as too threatening to consciously resolve. Today, this concept is termed conversion disorder and refers to the subconscious act of turning affective problems into physical expressions (Violon, 1987). Conversion disorders are typically associated with feelings of guilt, hostility, and resentment (Violon, 1987). Furthering the theory postulated by Freud, Engle (1959) argues for a personality type that he terms the "pain-prone patient." $\mathrm{He}$ links this personality with feelings of punishment, aggression, guilt, sexuality, and/or loss of a love object. In addition, he maintains that persons suffering from psychogenic pain were raised by punitive or abusive parents. As a consequence, they inflict self-punitive behavior that may include masochistic traits (Knorring, Perris, Eisman, Erickson, \& Perris, 1983). Blumer and Heilbronn (1982) support Engle's psychogenic model in stating that the pain-prone disorder is a vague psychobiological entity and, more specifically, an expression of a muted depressive state. They conclude that pain-prone patients somatically express masked emotional conflict.

A number of studies challenge the belief that there is a "pain-prone patient" and that these patients are psychologically homogeneous (Carlsson, 1986; Gamsa \& VikisFreibergs, 1991; Wade, Dougherty, Hart, \& Cook; Watson, 1982). In a study assessing 
patterns of personality structure among chronic pain patients, Wade, Dougherty, Hart, \& Cook (1992) conclude that chronic pain patients typically present with a relatively normal underlying personality structure. Likewise, results of a similar study assessing neurotic tendencies among chronic pain patients did not support the belief in a hysterical personality pattern (Watson, 1982). While pain patients may report substantial depressive sympotmology, there is no evidence linking this depression with depressive personality characteristics (Carlsson, 1986). In a study examining the relationship between pain and twenty psychological variables, Gamsa and Vikis-Freibergs concludes that the emotional disturbances associated with chronic pain are more likely to be caused by pain than they are to generate pain (Gamsa \& Vikis-Freibergs, 1991). While pain was related to current disturbances, there was not a relationship between events preceding pain onset and current pain (Gamsa \& Vikis-Freibergs, 1991). Screening for patterns of psychological illness and premorbid characteristics in four chronic pain populations, Mersky, Lau, Russell, Brooke, Tames, Lappano, Neilsen, Tilsworth (1987) found that childhood experience as seen by patients did not correlate with personality. Further, patients with diagnosed psychological illness were not differentiated from those without psychological illness according to the extent of somatic complaints reported.

\section{Anxiety/Fear}

The role of anxiety in relation to chronic pain is prominent in recent literature (Asmundson \& Taylor, 1996; Phillips, 1987; Wade, Dougherty, Hart, Rafi, \& Price, 1992; Watson, 1982). Anxiety has been shown to be the single most important predictor of pain unpleasantness and behavioral adaptation (Wade, Price, Hammer, Schwartz, \& Hart, 1990; Wade, Dougherty, Hart, \& Cook, 1992). Dworkin, Harstein, Rosner, Walthr, Sweeny, \& Brand (1992) found that the sole measure of anxiety during the acute pain 
stage differentiated those persons who developed chronic pain from those who did not. Similarly, McCracken, Zayfert, and Gross (1992) found that scores on the pain anxiety symptoms scale (PASS) predicted level of pain related disability and limits in daily functioning. Anxiety is the result of fearful concern. Fear of pain, resulting in heightened anxiety, may play an important role in the maintenance of chronic pain (McCracken, Zayfert, \& Gross, 1992). Therefore, whether physical or psychological in origin, chronic pain patients may be comprised of acute patients who have a particularly heightened fear of pain (Caldwell \& Chase, 1997). In relation to fear of pain Reis (1991) classified two other fundamental fears. The first, fear of injury, illness, or death, includes fears of elongated suffering and disability. Secondly, fear of negative evaluation includes fear of social rejection, censure, and ridicule. These fears may play an important role in magnifying anxiety (Asmundson \& Taylor, 1996).

One result of living in a constant state of fearful anticipation/anxiety may be the adoption of avoidance behavior. In fact, it appears that avoidance is the most prominent of the pain behaviors (Phillips, 1987). This avoidance is not confined to movement but also encompasses withdraw from personal non-physical activities and social interactions in particular (Phillips, 1987). Support has been found for the belief that anxiety sensitivity indirectly promotes escape/avoidance through its tendency to heighten fear of pain (Carlsson, 1986). The extent of avoidance behavior is determined by both the overall preference for reduced pain/discomfort and the expectation that exposure to certain stimuli will exacerbate pain (Phillips, 1987). In a sample of chronic lower back pain patients, beliefs regarding anticipated work related pain were found to be more 
specific determinants of disability and work loss than biological measures of pain (Waddell, Newton, Henderson, Sommerville, \& Main, 1993).

Avoidance behavior is a spontaneous response to acute injury (Phillips, 1987). However, it can be a maladaptive response to chronic pain. Instead of positively affecting level of pain, it seems that avoiding stimulation actually leads to an increased intolerance of that stimuli (Phillips, 1987). Avoidance typically decreases feelings of self-control of pain which, in turn, leads to further withdrawal from normal activities and heightened intolerance (Phillips, 1987). Accordingly, it is likely that avoidance reduces self-efficacy in that it increases expectations of pain in relation to stimuli. This behavior is self-defeating in that pain-related thoughts and beliefs are reinforced by the behavior that consequently creates them. While anxiety sensitivity is normally associated with overpredictions concerning levels of pain intensity, it is possible that individuals may underpredict potential levels of pain (Murphy, Lindsay, \& de C Williams, 1997). Overprediction may increase inappropriate avoidance behavior. Conversely, underprediction may be associated with failure to avoid when appropriate (McCracken, Gross, Sorg, \& Edmands, 1993). A pain induced experiment by Arnts and Peters (1995) found that patients with chronic back pain tended to significantly underpredict degrees of pain while control subjects had reasonable accurate predictions. Thusly, it may be concluded that one of the most effective ways to treat chronic pain may be through the manipulation of avoidance behaviors (Phillips, 1987).

\section{Depression}

Depression is the most common psychological disturbance associated with illness (DeVellis, 1993). However, there is variability among the literature concerning the relationship between chronic pain and depression. Some research has indicated that 
depression is linked with chronic pain (Brown, Nicassio, \& Wallston, 1989; Dworkin \& Gitlin, 1991; Haley, Turner, \& Romano, 1985). For example, in an article reviewing the clinical aspects of depression in chronic pain patients, Dworkin and Gitlin (1991) conclude that depressive disorders are an integral component of the chronic pain experience. Further, it has been estimated that as many as $87 \%$ of chronic pain patients are suffering from depression (Lindsay \& Wyckoff, 1981). Conversely, a number of studies have reported that chronic pain and depression are not correlated (Ahles, Yunus, \& Masi, 1987; Pelz \& Mersky, 1982; Pilowsky, Chapman, \& Bonica, 1977). A study assessing depression in relation to primary fibromyalgia syndrome disproved the hypothesis that the presence of chronic pain in the absence of an organic pathology is a variant of depressive disease (Ahles, Yunus, \& Masi, 1987). Likewise, an assessment of pain, depression, and illness behavior in a pain clinic population of 100 indicated a low degree of depressive affect with few patients manifesting depressive syndrome (Pilowsky, Chapman, \& Bonica, 1977). Similarly, in an article discussing the prevalence of depression in relation to arthritis DeVellis (1995) concludes that while a significant minority of individuals living with rheumatic disease suffer from depressive disorders, the majority do not.

In regard to those persons reporting both chronic pain and depression, a number of studies have found a positive correlation between depressive symptomology and pain experience (Dworkin, Richlin, Handlin, \& Brand, 1986; Hawley \& Wolfe, 1988; Haythornthwaite, Sieber, \& Kerns; 1991; Parker \& Wright, 1995). In a study examining the relationship between depression and a constellation of pain-related variables, Haythornwaite, Sieber, and Kerns (1991) found that depressed pain patients, as compared 
to a non-depressed group, reported greater pain intensity, greater interference due to pain, and more pain behaviors. Accordingly, depressed patients may be more likely to report constant rather than intermittent pain (Dworkin, Richlin, Handlin, \& Brand, 1986). In addition to the physiological consequences, it has been found that depressed patients report greater loss of ability for recreational and social activities (Doan \& Wadden, 1989). A study investigating the effect of depression among persons with myofascial pain disorders and arthritis concluded that more severe depression was significantly associated with more severe pain, conflict about pain, and less network and social support (Faucett, 1994). A culmination of factors link depression with increased anxiety, pain intensity, pain behavior, muscular tension, and psychastheria (Asmundson, 1996; Knorring, Perris, Eisman, Erickson, \& Perris, 1983). Thusly, the treatment of chronic pain in conjunction with depression may be enigmatic for both patients and practitioners. 


\section{III.}

\section{Social Support}

Social support is defined as the relationship that exists within social networks. Social networks consist of those people with whom we have contact and who, as a whole, help to form both our environment and our identity. They include both intimate relationships such as those with family, a spouse, close friends, and diffuse relationships including co-workers, doctors, peers, and social acquaintances. Social support within these structural networks includes the functional areas of emotional, appraisal, informational, and instrumental support/tangible aid (Glanz, Lewis, \& Rimer 1996).

In the absence of stressful events, a person's embededness in a social network may directly promote both mental and physical health. On the other hand, in times of stress, pain may act as a buffer, helping a person to cope with these mental and physical stressors (Cohen and Wills, 1985). Cohen and Wills (1985) postulate that whereas functional support exchanges are most effective in the presence of a stressor, the effects of structural support are present regardless of that stressor. Therefore, it can be hypothesized that both the direct and buffer effects of social support may act simultaneously and in accordance with varying situations (Cohen and Wills, 1985).

Receipt of positive or helpful support from friends and family has been linked to decreased levels of depression and improved functional status among chronic pain patients (Goodenow, Reisine, \& Grady, 1990; Revenson, Schiaffino, Majerovitz, \& Gibofsky, 1991; Weinberger, Hiner, \& Tierney, 1987). Likewise, amount of involvement in social networks has been significantly correlated with heightened levels of personal well-being (Patrick, Morgan, \& Charlton, 1986; Turner \& Noh, 1988; Weinberger, Hiner, 
\& Tierney, 1987). In a study examining the direct and buffer effects of various aspects of social support on depressive symptomology in persons with arthritis, Pennix, Van Tilberg, Deeg, Kriegsman, Boeke, \& Van Eijk (1997) found that, irrespective of the presence of arthritis, having both a partner and numerous close social relationships had a direct positive effect on psychological functioning. Furthermore, the receipt of support from diffuse social relationships seemed to buffer the influence of arthritis on negative psychological symptomology. Interestingly, this buffering effect was only significant in relation to individuals with severe arthritis. Within this group, having multiple diffuse relationships seemed to be even more beneficial than having few intimate relationships. Conversely, the results of a study by Goldberg, Kerns, \& Rosenberg (1993) emphasize the importance of close relationships in relation to personal well-being. Assessing perceived pain-related spousal support, they found results that support the social support buffering model. Among patients with low levels of activity (e.g. personal, social, household, outdoor), perceived spousal support in relation to pain expression was associated with lower depression scores. However, among patients who reported high levels of activity, spousal support in relation to pain expression did not affect levels of depression.

It may be that the quality, not quantity, of one's social relationships determine potential positive affect. In several studies, perceived adequacy of social support has been shown to be a more significant predictor of emotional well-being than availability (Fitzpatrick, Newman, Archer, \& Shipley, 1991; Goodenow, Reisine, \& Grady, 1990). In a study assessing a group of headache sufferers, these individuals, as opposed to a control group, were significantly less satisfied with their social support and scored lower on 
measures of appraisal support, esteem, belonging and tangible aid (Martin \& Soon, 1993). A cross-sectional interview study of 194 women living with rheumatoid arthritis found that quality of social support significantly affected pain-related function and depression (Goodenow, Seisine, \& Grady, 1990). Similarly, comparing both crosssectional and longitudinal results of a study assessing the impact of rheumatoid arthritis on social relationships, Henderson, Byrne, \& Duncan-Jones (1981) found that whereas cross-sectional results associated both availability and adequacy with psychiatric morbidity, longitudinal results found only adequacy to be significantly related to psychiatric well-being.

The perception of support from close relationships, particularly within a marriage, may influence the experience of both pain and associated distress (Kerns \& Turk, 1984, 1990). It is hypothesized that, in determining both the severity and disability associated with chronic pain, the spouse may assume a moderating role (Kerns \& Haythornthwaite, 1988). Rowat and Knaff (1985) postulate that uncertainty concerning pain is central to spousal distress. Accordingly, they found that highly distressed spouses were more likely to respond supportively to chronic pain than to ignore it. Thus, spousal distress may play a role in determining pain reinforcement. A study by Block, Kremer, \& Gaylor (1980) found that patients reporting that their spouses were non-solicitous in response to pain behavior reported significantly lower pain levels than those reporting that their spouses were solicitous in response to such behavior. Likewise, a study by Flor, Kerns, \& Turk (1987) yielded similar results, concluding that the spouse may be a potential source of reinforcement behavior. 
While social interactions may be a source of support for individuals living with chronic pain, they may also serve as potential stressors. A study by Revenson (1991) assessed social network interactions as potential sources of both support and stress for individuals living with chronic illness. While receipt of positive support from friends and family was related to decreased depression, receipt of problematic support was related to increased depression. Likewise, patients who reported both little support and a greater number of problematic interactions experienced the highest level of symptoms. In a study investigating the contributions of interpersonal conflict in relation to chronic pain, Faucett \& Levine (1991) conclude that the negative or conflictual, as opposed to the supportive aspects of personal relationships, contributes to reports of sensory pain. Similarly, Shinn, Lehmann, \& Wong (1984) argue that negative social interactions are more accurately construed as stress rather than support. Pennix,Van Tilberg, Deeg, \& Kriegsman (1997) found a positive correlation between instrumental support received and depressive symptomology in regard to respondents with mild arthritis. It can be theorized that among more physically functional persons, receiving heightened instrumental support could cause feelings of helplessness or dependency on others. In turn, these feelings may be correlated with a heightened depressed state (Smith, Dobbins, \& Wallston, 1994).

In some cases, it may be that pain pathology determines social reactions and subsequent types of support offered. The absence of known organic pathology may increase social uncertainty as to the cause or intensity of pain. Likewise, the contributions of psychological factors in relation to pain experience may be called into question (Faucett \& Levine, 1991). In a study involving patients living with back pain of 
undetermined etiology, the attribution of pain to psychological difficulty was correlated with increased spousal distress and marital dissatisfaction (Block, Kremer, \& Gaylor, 1980). Concerning organic versus non-organic pain pathology, a comparison between patients with myofascial disorders and arthritis yielded interesting results (Faucet \& Levine, 1991). Patients with myofascial disorders reported significantly more conflict from their social network than did those patients with arthritis. Further, results indicated that patients with myofascial disorders were more likely to be met with punishing responses from their significant other. While increased conflict in close relationships predicted less intense sensory and affective arthritis pain, increased conflict predicted more intense pain within myofascial disorders. Thusly, the authors conclude that the effects of social relationships on pain intensity may depend largely on the presence or absence of physical evidence validating the patient's pain. Among individuals with nonorganic chronic pain, increasing social doubt may lead to feelings of stigmatization. Accordingly, these feelings have been correlated with increased reliance on household members for support (Lennon, Link, Marbach, \& Dohrenwend, 1989). This creates a double-edged sword in that increasing doubt increases reliance, which, in turn, heightens initial skepticism. However, for some patients, increased pain behavior and depression may result in a lack of appropriate spousal support rather than be caused by it (Goldberg, Kerns, \& Rosenberg, 1993). 


\section{IV.}

\section{Explanatory Models}

Explanatory models are the means through which sick persons, their families, and practitioners interpret various aspects of both illness and treatment (Kleinman, 1988). An illness narrative, the primary component of an explanatory model, is an individual's story of the distinct course of events and consequences related to their particular illness. Kleinman (1988) states that patients order their experience of illness through these personal narratives. Further, he maintains that in addition to being a reflection of illness experience the personal narrative contributes to the experience of symptoms and suffering. In relation to chronic pain, Jackson (1994) states that the ways in which pain sufferers connect pain to both their bodies and their identity is a crucial element of the pain experience. In accordance Helman (1985) states that the occurrence of any disorder may be explained not by the characteristics of a particular disease entity but in reference to the biological, psychological, and social aspects of a person's life. Thus, we can only understand the pain experience when we explore the individual's concept of the pain condition and it's relation to the self. Kleinman (1988) concludes that explanatory accounts seem to respond to any or all of the following questions:

\section{Etiology:}

- What is the cause of the disorder?

- What is the source of improvements and exacerbations?

Onset:

- Why did it have its onset precisely when it did?

Pathophysiology:

- What does the illness do to my body? 


\section{Course:}

- What course is it following now and what course can I expect it to follow in the future?

- How can I control the illness, its exacerbation, and its consequences?

- What are the principal effects the illness has had on my (our) life?

- What do I most fear about this illness?

Treatment:

- What treatment do I wish to receive?

- What do I expect of the treatment?

- What effects of the treatment do I fear?

The answers to these questions provide meanings influenced by physical, personal, and social meanings:

\section{Physical Meaning}

Chronic pain is often characterized by a condition in which perceived pain severity and physical limitations can not be physiologically explained. As a consequence, pain patients may feel pressure to convince others that their pain is "real." Typically, it is the communication of symptoms, through both pain behavior and language, that signify this "real" distress and/or disability. Kleinman (1988) states that in order to define symptoms key words take on heightened significance. For example, a person may have a "pounding headache" or an "aching back." Thus, word choice can influence the behavior of others in a person's attempt to receive support, distance others, or convey emotion. Contemporary society values states of independence, fitness, youthfulness, social success, and control over bodily functions and emotions (Helman, 1985). Thus, in order to keep self-image intact, pain may be defined as a state that is separate from the self, an independently existing entity. Helman (1985) discusses the concept of 'non-self', a definition of illness and/or pain 
as something that is no longer a part of the body but, rather, is something intrusive upon it. Thus, an individual may consider pain etiology to be beyond personal control.

\section{Psychological Meaning}

Jackson (1994) states that pain is emotion, not merely a condition that has an overlay of emotion. Early analysists interpreted pain symptoms as symbols with personal significance. They believed that these 'conversion disorders' were in reality psychological conflicts materializing as somatic complaints (Engle, 1959; Freud, 1917). In response to these theorists, Kleinman (1988) contends that a single-minded search for psychoanalytic explanations can dehumanize the patients as much as a purely biomedical investigation. In a study examining the explanatory models and self-perceptions of patients with either respiratory or gastrointestinal disorders, Helman (1984) found marked differences in the models used by these two groups. Persons with asthma typically attributed their illness to external influences, both social and physical. The onset of an asthma attack was seem as an attack "from without" on both the respiratory system and the self. While persons in the gastrointestinal group also attributed illness to external influences, they saw these influences as being internalized, transformed into negative emotions, and being allowed to accumulate. Both groups, however, responded that pathogenesis may be aided by personality type, with the majority describing themselves as too sensitive, nervous, tense, and vulnerable to outside events. 


\section{Social Meaning}

The personal and subjective sensation of pain depends on social action to make it "real" or to verify its existence (Jackson, 1994). Helman (1985) ascertains that illness realities constructed between the clinician and patient link physical symptoms to the wider world of social and moral values. The results of his study comparing the explanatory models of two patient groups revealed that the majority of subjects believed that negative social relationships could adversely affect their condition or explain its etiology. Similarly, subjects maintained that good relationships could affect their health in a positive way or could even cause, maintain, or restore health.

Through the analysis of personal explanatory models, clinicians and researchers may come to recognize both the personal significance and social uses of illness. This exploration is in opposition to the typical structure of a medical system that pursues the biological mechanisms of disease only. Kleinman (1988) states that a primary clinical task should be the empathetic interpretation of a patient's life story that transforms illness into biography. He maintains that through the examination of the personal narrative it is possible to break the cycles that signal distress. 


\section{Conclusion}

"For the seriously ill, insight can be the result of an often grim, though occasionally luminous, lived wisdom of the body in pain and the mind troubled. For family members and practitioners, moral insight can emerge from the felt experience of sympathy and empathy.” - Arthur Kleinman

Chronic pain is both personal and subjective. Therefore, when examining this type of pain it is necessary to consider multiple factors that may both contribute to and be a consequence of the personal pain experience. Physiologically, pain may be the result of disease or injury. However, in some cases chronic pain exists with no known organic etiology. Coping with this type of pain is often physically, personally, and socially complex.

The personal effects of living with unceasing pain vary among individuals. Research concludes that possible effects include anxiety, frustration, anger, fear, and depression (Wade, Price, Hammer, Schwartz \& Hart, 1990; Devellis, 1993; Asmundson \& Taylor, 1996). Accordingly, the effects of chronic pain on one's social support system may vary. Positive support includes emotional, appraisal, informational, and instrumental support/tangible aid (Glanz, Lewis \& Rimer, 1996). It is theorized that positive social interaction may either directly promote health or act as a buffer, helping a person to cope with existing health-related obstacles (Cohen \& Wills, 1985). Conversely, negative social effects may arise as one's social network struggles with the negative aspects of the pain experience. Negative or conflictual social interaction has been positively correlated with increased sensory pain (Faucett \& Levine, 1991). 
Kleinman (1988) suggests that the chronic pain experience may best be understood through the examination of explanatory models. These personal narratives address an individual's beliefs and attitudes regarding pain etiology, onset, pathophysiology, course, and treatment. The telling and interpretation of one's life-story may shed light on the physical, psychological, social, and cultural meaning of pain. This process is essential in understanding both the causes and consequences of chronic pain (Kleinman 1988). 


\section{Methods}

\section{Overview of In-depth Interviewing}

In-depth interviewing is a qualitative method of data collection used in order to obtain descriptions of people's perceptions and experiences. Qualitative research, by design, allows the researcher to gather information about actions, interactions, and belief systems in order to reflect on their meaning and systematically draw conclusions. Therefore, this is an appropriate method of assessing the perceived causes and consequences of chronic pain. In this study, in-depth interviews were used in an attempt to uncover individual beliefs, attitudes, and explanatory models regarding the experience of living with chronic pain. Interviews were semi-structured with open-ended questions, allowing participants to freely discuss and expand upon any aspects of their experience that they feel are significant. There was no attempt by the interviewer to guide responses into predetermined categories. Rather, this is a collection of individual personal narratives.

\section{Sample}

The sample for this study was a convenience sample consisting of eleven women and one man, aged eighteen and older who are currently living with the chronic pain condition Fibromyalgia. Eleven out of the twelve participants were married. All participants were Caucasian. Subjects were recruited from a community fibromyalgia support group in West Virginia. This non-profit group is open free of charge to any member of the public, is community run, and is not affiliated with any hospital or university. The option to participate was given to every member of the group and every interested person was included until the quota was met. 


\section{Data Collection}

The acting president of the fibromyalgia support group was contacted to inquire whether group members might be interested in learning about this study. After receiving a positive response from the president of the group, initial contact was made with group members during a monthly group meeting. During the meeting, the study proposal was explained and members were invited to participate. Interested persons gave their phone numbers and were later contacted to confirm and decide upon an interview date. Fifteen individuals originally volunteered for the study. However, two people canceled and one person had an interview that could not be transcribed. Therefore, the final sample size was twelve. Approval for the study was obtained from the West Virginia University Institutional Review Board. Data was collected using one-on-one semi-structured interviews lasting approximately one hour. Informed consent was gained before participation began. The interviews were tape-recorded and were conducted in each participant's home. A qualitative interview method was used in order to elicit individual's descriptive explanatory models of pain. Subjects were asked open-ended questions regarding the physical, personal, and social effects of living with chronic pain. Each participant was encouraged to discuss any aspect of the personal pain experience that he or she feels is significant. When appropriate, the interviewer interceded with a guided question. Interview questions include:

\section{Primary Question:}

Tell me about your experience with chronic pain.

\section{Secondary Questions:}

(1) How long have you been living with chronic pain? 
(2) Typically, on a scale from 0 (no pain) to10 (worst pain) how intense is your pain?

(3) Why did your pain have its onset when it did?

(4) What course is it following now?

(5) What course are you expecting in the future?

(6) What factors exacerbate your pain?

(7) What techniques (coping skills) do you use to reduce your pain?

(8) How has pain affected you personally?

(9) How have your friends and family reacted to your pain?

(10) How has pain affected your quality of life?

(11) Can you work?

(12) Can you engage in recreational activities/exercise?

(13) What treatments/medications are you receiving?

(14) What do you most fear about your pain condition?

\section{Data Analysis:}

Data was analyzed using a descriptive analysis method. NUDIST, a text analysis software package for microcomputers, was used to organize and analyze the data. Data was coded according to Kleinman's categories for explanatory models. These categories included: (1) Etiology (2) Pathophysiology (3) Onset (4) Course and (5) Treatment. Reports were then generated and interpreted by the researcher in order to draw conclusions regarding common patterns emerging within the group. The common themes in participant's explanatory models will be presented with supporting individual quotes. 


\section{RESULTS}

\section{Sample Characteristics}

Twelve participants, eleven women and one man, were included in the sample. Group members had been living with chronic pain typically from five to ten years. Accordingly, responses on a pain intensity scale of 0 (no pain) to 10 (worst possible pain) yielded a pain index of seven.

\section{Etiology}

\section{$\underline{\text { Unknown }}$}

Study participants were, in general, unsure as to what causes fibromyalgia. Four participants cited the physical damage resulting from a car accident as the primary cause of their fibromyalgia. The other eight participants cited either emotional stress or an unknown factor(s) as causing their condition.

Fibromyalgia, as a chronic pain disease, is highly enigmatic. Primarily, fibromyalgia is a diagnosis of elimination, meaning that individuals are typically diagnosed as a result of ruling out all other possible illnesses. As of yet, the medical community has not determined the specific cause or causes of this condition (Catalano \& Hardin, 1996). Therefore, the observed participant uncertainty regarding etiology does not show lack of appropriate medical knowledge within the group. While possible causative theories were expressed, none were done so with absolute certainty:

"I have no idea. They are talking now about the antipolimer antibodies. That sounds like something environmental - plastics, polimers, I don't know.” (Participant 11). 
"There are a lot of theories: it could be viral, it could be hereditary, could be

trauma. There are a lot of theories." (Participant 4)

\section{$\underline{\text { Stress }}$}

Although little is known about the physiological mechanisms of chronic pain, the majority of participants (11 out of 12) expressed the belief that stress, either physical or emotional, was the primary contributing factor in the development of their condition. Explanations centered on the opinion that fibromyalgia occurred as a direct result of surviving a major physical or personal life event or trauma. Physically, car accidents were the primary cited cause of physical stress. Emotional stressors varied, including an array of personal/emotional events such as marital difficulties, work-related problems, and family stressors:

"I had just finished a very intense two years of a master's degree program with an internship at a hospital. And I was under a lot of stress, but I didn't have any pain at that point at all. So, I had just completed that and then I began to wonder if it was kind of the let down then of having suffered that stress for two years. Because it was about three months after I completed that, that this started." (Participant 10)

"The reason why I was under stress is that my husband owned a company and we were experiencing and undergoing a very violent labor strike. And so the basic fear I was experiencing was fear of safety for my children, myself, and my husband. There is a direct correlation. As that went on months by months, my pain got worse and worse and I started to develop more and more symptoms. I think I was holding up great. I mean, honestly, I think that's why the fibromyalgia occurs: because I reacted mentally so well and held it together so well for myself and my kids and everybody else that was affected 
by the situation. The stress I was under physically broke down my body." (Participant 12)

"They say you are supposed to have five years to get over each trauma, but within five years, I had several traumas and I just didn't have time to cope with it. I had no choice, so that is the only thing I can think of. It's like an emotional breakdown of the fight or flight response.” (Participant 4)

\section{$\underline{\text { Frustration }}$}

Regarding disease etiology, a theme of individual frustration ran throughout the group. Because of the mysterious nature of fibromyalgia, frustrations concerned both the uncertainty of a causative factor(s) coupled with lack of physician response. During the initial onset of fibromyalgia, participants reported frustration in receiving a diagnosis coupled with the fear that the diagnosis might be one of a terminal illness, primarily multiple sclerosis or cancer:

"I had absolutely no idea. I was speculating that it would possibly be multiple sclerosis, or lupus, or some type of joint disease." (Participant 12)

"I feel like I have been raped. Because I took care of my body. I ate good. I didn't smoke. I didn't drink. I didn't do drugs. And I don't understand why this is happening." (Participant 4).

Regarding physician support, participants expressed frustration concerning attempts to receive both medical attention and a concrete diagnosis. Individuals did not typically blame the medical community for their difficulties in obtaining a diagnosis. Rather, they tended to see fibromyalgia as a condition that is enigmatic for everyone 
involved, including physicians. However, feelings of being dismissed or not taken seriously enough by physicians was common within the group:

“That's one thing that being sick has taught me, being sick, that doctors aren't God. You know, a lot of society's view is still, 'Oh yeh, you know, the doctor can fix me. The doctor can help me.' The doctor is human. The doctor is not God and you really have to stand up for yourself when you are chronically sick." (Participant 6).

"I had all these symptoms and then the doctors wouldn't find anything and then they would say, “It's just your nerves. You'll just have to de-stress your life. It's all in your head and if you just go exercise and you do this and you do that you will be just fine. They never did any searching." (Participant 5).

\section{ONSET}

A diagnosis of fibromyalgia was typically received approximately one year after symptoms onset. Following initial diagnosis, participants reported experiencing pain onset due to various exacerbating factors. However, the majority of participants cited overdoing as the principle factor contributing to a pain flare. Likewise, the majority reported that their symptoms increase as a result of emotional stress:

"If I overdo. Like when we moved, I was trying to unpack and there were days when I couldn't even get out of bed. There were times when I couldn't even stand up on my legs because of the pain” (Participant 4)

"I was in a stressful business that I was part owner of for three years and I actually ended that business partnership six months ago. At the end of the business, it was so stressful that the fibromyalgia was really getting the best of me." (Participant 1). 
Interestingly, weather was commonly cited as an exacerbating symptom. Although type of weather inducing a symptoms flare varied, it was consistently reported to increase symptoms. Accordingly, diet was believed to play a moderating role throughout the group. Food noted as inducing symptoms included alcohol, fatty foods, processed foods, and foods containing additives and preservatives.

Noted sources of improvement were limited, with the majority of participants stating that they have no way of controlling their pain. While the majority of participants were on some kind of pain medication, this was not cited as a continually effective source of improvement. Some individual means of improvement among participants included diet, exercise, and spiritual practice:

"I think that the exercise, in combination with the nutrition and being aware of your diet, is extremely important. I think I have to say this too, taking care of your mind is important both emotionally and physically. I think the kinder I am to myself spiritually, the better I feel, the better my body feels, the better my mind feels."

\section{(Participant 1)}

\section{Pathophysiology}

As with etiology, the majority of study participants were confused in regard to disease pathology. The present scientific lack of understanding regarding fibromyalgia by the medical community makes it extremely difficult to fully understand the physiological mechanisms of this condition. However, a common belief both in the literature and within the group is that fibromyalgia is multi-faceted, with individuals having varying responses to a number of physical, personal, and social conditions: 
"Sitting too long. Sitting in a car too long. That triggers my back problem.

Overdoing, like going to a festival and spending the day or half a day is too much. I've got all these food allergies and all these allergies to perfumes and things like that, so if we go to the mall shopping, I can't go by the department store because I get a migraine. There are just a lot of things to contend with. We don't have big parties anymore." (Participant 7)

\section{Future Course}

A common belief throughout the group was that no successful treatment will be found for fibromyalgia. The majority of study participants believe that they will never fully recover from this pain condition. Therefore, it is mainly regarded as something with which one must learn to live. The theme of frustration reemerged here, as individuals worked to decide the most effective ways in which to cope with pain both currently and in the future:

"I have an optimistic outlook. I am hoping, but then in the back of my mind I'm thinking that I'm not. Because I think that if I would have gotten better I would have by now." (Participant 5)

"There is one part of me that is hopeful and this one part of me is hopeless. But, the hopeful part is like, yea, I think I am going to get a certain percentage better. It could happen. And then there is this other part of me that is scared: like, I don't know if it is going to happen and what if it doesn't happen?" (Participant 6)

“You just kind of deal with it. And I don't think it's going to end. It is just going to become more and more manageable." (Participant 7) 


\section{Fear/Anxiety}

A theme running throughout the group was that of fear and anxiety regarding the future with chronic pain. Participants commonly expressed both fear and anxiety in relation to the belief that pain may interfere with the achievement of both future goals and happiness:

"I cry every time I think about it because I don't know if I can live like this for the rest of my life. I just have to think I had so many goals and hopes and different ideas, but now I have to adjust my thinking and say, "Well, I can only do this right now and I have to live with it. I have no other choice. (Participant 4)

"I mean, it scared me at one pint, especially when I thought, "My job is done. I've got to quit. I have been in the field for 23 years and I am not ready to give it up. I love it." (Participant 5)

Personal Effects

The chronic experience of pain, coupled with a tendency toward doubt regarding both treatment and cure, was reported to result in varying emotional responses among the participants. Personally, frustration, coupled with a damaged self-concept, was the most commonly reported emotion. Individuals struggled with not being able to do those things that they had always done with ease in the past. The inability to carry out and enjoy former activities lead to distress with most participants. Accordingly, participants reported bouts with depression as a result of this frustration. It was commonly believed that perceived inability to function fully leads to depression, not that depression leads to decreased activity: 
It really gets frustrating when you can't do the things you've always done." You get really upset and depressed because you feel like "Well, I can't do anything without paying for it.” (Participant 3)

"Probably my hardest challenge is to keep myself going as far as self-concept, feeling that I am an accomplished person, that I can do anything at all, because I just feel like I am totally not worth being sustained on this earth.” (Participant 7)

"I am under stress, I think I get depressed at times, but my depression is from the things that I can't do.” (Participant 5)

"I've had to lower my expectations of myself." (Participant 11)

A person with fibromyalgia typically looks quite healthy. Participants cited this fact as leading to feelings of being misunderstood. Participants feared doubt by both their social networks and, in some cases, by the medical community. This doubt, either real or anticipated, lead the majority of persons to report that they view fibromyalgia as a personal problem and one that is not readily discussed with friends and family:

"A lot of people who do not understand it, they do not respect it and think, "Oh well, you know, she probably needs to see a psychologist. So, no, I really don't discuss it." (Participant 1)

\section{$\underline{\text { Social Effects }}$}

In general, respondents reported decreased social activity as a result of living in chronic pain. Participants primarily attributed this decrease in social relationships to their inability to participate in former social activities. Accordingly, participants expressed feeling misunderstood by extended social networks: 
"I've had lots of problems with people not understanding, not being able to change it. Not understanding why I can't keep up with them or why I can't do certain things.” (Participant 6).

Although a decreased social network was reported as an effect of living with chronic pain, the majority of participants reported having at least one supportive relationship. Most often, participants noted their spouse as a source of positive emotional and instrumental support. Individuals also reported that friendships made after their diagnosis with fibromyalgia tend to be more supportive than those established prior to disease onset:

My friends that knew me all my life kind of didn't take it seriously. They thought I was over-exaggerating. My friends that I've made since I've been sick know my activity level and they are a lot better. But the ones that knew me before, they don't know how to deal with it and so they just stay away.” (Participant 11)

Disappointment/Frustration

Because of the effects of chronic pain, a number of respondents reported that they are often unable to care for their family as well as they have in the past. Limitations included domestic areas such as cooking, cleaning, laundry, and home maintenance as well as social areas such as traveling and attending various social events with children, spouse, or extended family. A theme of disappointment and frustration emerged as participants expressed the belief that they are frequently letting themselves and/or their family down:

"I've always done things for them. And my grandson's getting baptized on Sunday and I always made the cake. Now, I can't decorate them because it really 
bothers my hands. So, I have problems, you know, that I can't do things for them." (Participant 3)

"I don't cook like I used to. We used to have big meals every night for supper, but now we have sandwiches more than anything else. I just don't feel like doing it." (Participant 5)

"I feel like my husband is being cheated out because I am not out helping to make more money to give us a better level of income." (Participant 4)

\section{TREATMENT}

There is little known about the treatment of fibromyalgia. Therefore, participants frequently reported unsuccessfully experimenting with different treatment options. Employed treatment primarily consisted of pain medication and sleeping pills. Typically, participants expressed the desire to limit pain medication due to the fact that it is often ineffectual or becomes ineffectual with time. Anti-depressants were frequently prescribed in response to the personal difficulties arising from living with chronic pain. Additionally, it is theorized both in the medical literature and by participants that antidepressants may, in some cases, inhibit pain transmission by increasing serotonin levels in the brain. There were mixed feelings within the group regarding the effectiveness of anti-depressants. However, it was generally agreed that sleeping pills are helpful, as sleeplessness is a common complaint of persons living with fibromyalgia:

"I take Soma. It's a muscle relaxer. But I try not it take it unless I really have to take it because, again, that's putting more toxins back into my body. I am on Rolifin but I haven't taken that for probably four or five months. I don't want to take that either. I don't want to take anything if I don't have to, other than vitamins." (Participant 11) 


\section{Frustration}

The theme of frustration reemerged as participants discussed the ways in which they attempt to treat fibromyalgia. Those participants with a more recent diagnosis tended to be more frustrated and anxious than those who have been diagnosed for a longer period of time. As an acceptance of living with the pain associated with fibromyalgia increased, frustration tended to decrease. However, frustration in treatment was present in every study participant:

“Finding out what works best and what doesn't work, I'm really paying attention to that. Before, it was like, I'm going to this next doctor and he's going to give me the special, you know, I am going to read this book and it's going to be this special thing, diet or whatever. I think it's just probably a balance with everything, and that I just have to accept what has been handed to me and I have to do the best I can to live with it."

\section{(Participant 7)}

\section{Conclusion}

Three major themes ran throughout the interviews. First, there was a general lack of understanding regarding the etiology and pathology of fibromyalgia. As this condition is, by nature, enigmatic, this is an expected occurrence. Secondly, the majority of participants expressed great frustration and/or anxiety in regards to pain etiology, the future, personal relationships, and treatment. Lastly, participants frequently reported spoiled social interaction as a result of living with chronic pain. Feelings of being doubted or misunderstood by one's previous social network were common. Thus, individuals typically viewed their illness as a condition that is best handled personally. 
Findings from these interviews with individuals with the chronic pain condition fibromyalgia are summarized in the table below:

\section{$\underline{\text { Table } 1 \text { Summary of Major Interview Findings on Explanatory Models of Chronic Pain }}$}

1. There was a general lack of understanding as to both the etiology and pathology of fibromyalgia.

2. There was a strong sense of personal frustration regarding the unknown causes of fibromyalgia.

3. Various factors including overdoing, stress, diet, and weather exacerbate symptoms.

4. The majority of participants noted that there is no truly effective way to consistently improve symptoms.

5. A common belief throughout the group was that no successful treatment will be found for fibromyalgia.

6. A feeling of fear and anxiety regarding the future was prevalent among participants.

7. Regarding the personal effects of living with fibromyalgia, frustration was the most commonly reported emotion.

8. In general, participants reported decreased social activity as a result of living with chronic pain.

9. A theme of disappointment and frustration emerged as participants expressed the belief that they are frequently letting themselves and/or their family down.

10. Participants frequently reported unsuccessfully experimenting with different treatment options.

11. Frustration in attempting to uncover successful treatment options was common throughout the group. 


\section{DISCUSSION}

\section{$\underline{\text { Major Findings }}$}

The most common explanatory model of disease etiology in this study focused on the overwhelming belief that fibromyalgia results as a reaction to either a physically or emotionally traumatic life event. Participants' responses supported a general belief that extreme stress causes a breakdown in the body's natural ability to resist illness. This finding supports Miller \& Kraus (1990) in concluding that pain may result from anxiety, stress, and tension. Proceeding their diagnosis with fibromyalgia, participants expressed confusion regarding both the etiology and pathology of fibromyalgia. Personally, a constant sense of frustration was the most noted effect of living with chronic pain.

Frustration was a common theme running throughout the narratives. Frustration resulted primarily from confusion regarding illness etiology and pathology, as well as from the inability to live up to perceived personal and social expectations. Respondents commonly expressed the belief that living with fibromyalgia has led to both personal and social disappointment.

Fear regarding the future was another consistently noted theme within the majority of narratives. A large majority of participants reported the belief that a cure for fibromyalgia will not be found. Thus, fear and anxiety resulted as individuals considered limitations that chronic pain may have on their future. Throughout the literature, anxiety has been found to be the single most important predictor of degree of pain unpleasantness and behavioral adaptation (Wade, Dougherty, Hart, \& Cook, 1992). Findings from this study support that literature. 
Phillips (1997) postulates that one result of living in a constant state of fearful anticipation and anxiety may be the adoption of avoidance behaviors. This can be seen throughout the narratives as respondents commonly expressed that they must eliminate and avoid those things that induce a pain symptoms flare. Participants also cited the frequent avoidance of previously enjoyed social situations as a way to control pain. As Phillips suggests, the extent of avoidance behavior is dependent upon expected pain discomfort and subsequent social repercussions.

It has been theorized that depression is the most common psychological disturbance associated with illness (Devellis, 1993). Results from this study, however, do not support that claim. While some respondents did report bouts with depressive feelings, none noted depression as a significant personal problem. Likewise, any depressive symptomology was expressed as resulting from feelings of frustration due to the limitations of pain. Reports of frustration and anxiety far superceded those of depression. However, feelings of spoiled social interactions were common throughout the group. The fact that participants in this study chose to seek support within a support group may mean that these individuals approach treatment in a different manner than those who do not and, as a result, may be less depressed. Therefore, although depression was not found to be prevalent within this group, it may exist among chronic pain patients who do not actively seek social support.

Results of this study strongly support Arthur Kleinman's concept of explanatory models. Kleinman (1988) maintains that the sick person and his or her social network create the meanings of chronic illness. This interpretation affects the ways in which a person views both the self and the illness. Thus, in order to truly understand and treat 
illness we must first view that illness within a personal framework. The personal narratives given by the participants in this study yield findings that exceed those of a traditional biomedical model. Living with an illness involves more than physiological mechanisms or biological pathology. Rather, it involves a variety of physical, personal, and social causes and consequences. This becomes amply evident through the examination of life stories.

In a study examining explanatory models in the narrative representations of the chronic illness experience, Garro (1994) concludes that through describing the effect of illness on individual lives, narratives also illustrate the ways in which shared understandings shape both the understanding and construction of individual experience. She maintains that the experience of illness may also alter the ways in which individuals view themselves, their present, their future, and their past. Further, she states that illness narratives are shaped by social context. The results of the present study support both this idea and the validity of explanatory models as a mode through which to interpret illness.

\section{Study Limitations}

This study has several limitations. Most importantly, because the study group is composed solely of individuals living with fibromyalgia, the results may not be generalizable to chronic pain sufferers as a whole. Further, they may not be generalizable to all persons living with fibromyalgia. There are certain characteristics about this group that may set it apart as a cohort. First, everyone included in the study participates in a support group Secondly, eleven out of twelve participants were Caucasian females. Therefore, results might not apply to persons of other ethnic backgrounds, nationalities, or men. Lastly, eleven out of twelve participants were married. Having a spouse may 
affect the ways in which a person lives with chronic pain. Therefore, the results may not be generalizable to individuals who are not married.

$\underline{\text { Implications and Future Research }}$

In order to increase the external validity of the findings, further research needs to be conducted including persons with various pain conditions, ethnic and national backgrounds, and marital status. Using larger sample sizes would also be beneficial.

The results of this study implicate the need for a multi-faceted approach in both understanding and treating the causes and consequences of chronic pain. Kleinman (1988) suggests that we can not truly understand the mechanisms of illness without first considering these mechanisms within a personal framework. The experience of living with chronic pain has multiple physical, personal, and social consequences. These areas, both alone and in combination, must be studied as factors that may positively or negatively impact a chronic pain condition. While medically based physiological research is essential to understanding pain; it alone is not enough. This knowledge may greatly impact the ways in which pain related topics are addressed within the healthrelated fields. 


\section{APPENDIX \\ CONSENT AND INFORMATION FORM \\ Explanatory Models of Chronic Pain}

INTRODUCTION. I have been asked to participate in this research study which is being conducted by Neely Thrush. Neely Thrush has explained the study to me and will be conducting the interview, which will take place in my home or place of choice. This study is being done in order to complete a class requirement for a Masters degree at West Virginia University.

PURPOSE OF THE STUDY. The purpose of this study is to investigate the experience of living in chronic pain.

PROCEDURES. This study will consist of 10 adults, all of whom are living with chronic pain. If I agree to participate, the interview will be audiotaped and will last approximately one hour. The interview will consist of open-ended, guided questions regarding my experience of living with chronic pain. Upon completion of all interviews, the data will be analyzed by the investigator. The audiotaped interviews will then be erased. I understand that I am free to ask questions about the study and the interview before signing the consent form. I understand that I am not required to answer any question or discuss any subject if I do not choose to do so.

Benefits. There are no known or expected benefits from taking part in the study. Risks and Discomforts. There are no known or expected risks or discomforts from taking part in this study.

Alternatives. The only alternative to being in this study is to choose not to participate. I understand that I can exercise this right at any time.

Contact Persons. For more information about this research I can contact Neely Thrush at (304) 284-9954 or her faculty advisor Dr. Irene Tessaro at (304) 293-7510. For information regarding my rights as a research subject, I may contact the executive secretary at the Institutional Review Board at (304) 293-7073.

Confidentiality. I understand that any information about me obtained as a result of my participation in this research will be kept as confidential as legally possible. My name will not be used on my audiotape and will not be referenced at any time. In any publications that result from this research, neither my name nor any information from which I might be identified will be published. I understand that the audiotapes will be kept in the possession of Neely Thrush and will be destroyed after completion of the study.

Voluntary Participation. Participation in this study is voluntary. I am free to withdraw consent to participate at any time during the study. There are no penalties for refusal to participate. I have been given the opportunity to ask questions about this research, and I have received answers concerning areas I did not understand. Upon signing this form, I will receive a copy. I willingly give consent to participate in this study.

Signature of Participant

Signature of Investigator
Date

Date
Time

Time 


\section{APPENDIX \\ PAIN INTENSITY SCALE}

Past six weeks:

\begin{tabular}{lllllllllll}
\hline 0 & 1 & 2 & 3 & 4 & 5 & 6 & 7 & 8 & 9 & 10 \\
$\begin{array}{l}\text { No } \\
\text { Pain }\end{array}$ & & & & & & & & & & $\begin{array}{c}\text { Worst Possible } \\
\text { Pain }\end{array}$ \\
\end{tabular}

Past Six Months:

\begin{tabular}{lllllllllll}
\hline 0 & 1 & 2 & 3 & 4 & 5 & 6 & 7 & 8 & 9 & 10 \\
$\begin{array}{l}\text { No } \\
\text { Pain }\end{array}$ & & & & & & & & & & $\begin{array}{l}\text { Worst Possible } \\
\text { Pain }\end{array}$
\end{tabular}

Past Year:

\begin{tabular}{lllllllllll}
\hline 0 & 1 & 2 & 3 & 4 & 5 & 6 & 7 & 8 & 9 & 10 \\
$\begin{array}{l}\text { No } \\
\text { Pain }\end{array}$ & & & & & & & & & & $\begin{array}{c}\text { Worst Possible } \\
\text { Pain }\end{array}$
\end{tabular}




\section{REFERENCES}

Ahles TA, Yunus MD, \& Masi AT. (1987). Is chronic pain a variant of depressive disease? The case of primary fibromyalgia syndrome. Pain, 29, 105-111.

Anderson KO, Keefe FJ, Bradley LA, McDaniel LK, Young LD, Turner RA, Agudelo CA, Semble EL, \& Pisko EJ. (1988). Predictions of pain behavior and functional status of rheumatoid arthritis patients using medical status and psychological variables. Pain, $33,25-32$.

Arnoff G. (1992). Evaluation and Treatment of Chronic Pain. Baltimore: Urban \& Schwarzenberg.

Arntz A \& Peters M. (1995). Chronic low back pain and inaccurate predictions of pain: is being too tough a risk factor for the development and maintenance of chronic pain? Behavior Research and Therapy, 33, 49-53.

Asmundson G \& Taylor S. (1996). Role of anxiety sensitivity in pain-related fear and avoidance. Journal of Behavioral Medicine, 19, 577-586.

Berry, J. (1992). Common misperceptions about chronic pain. American Pharmacy, 32, 68-69.

Block AR, Kremer EF, \& Gaylor M. (1980). Behavioral treatment of chronic pain: the spouse as a discriminative cue for pain behavior. Pain, 9(2), 243-252.

Blumer D \& Heilbronn M. (1982). Chronic pain as a variant of depressive disease: the pain-prone disorder. Journal of Nervous Mental Disorders., 170, 381-406.

Bruer J, Freud S. (1955). Studies on hysteria. Complete Psychological Works of Freud, stand. Edn., Vol. 2, Hogarth Press, London.

Brown GK, Nicassio PM, and Wallston KA. (1989). Pain coping strategies and depression in rheumatoid arthritis. Journal of Consulting and Clincial Psychology, 57(5), 652-657.

Caldwell AB \& Chase C. (1977). Diagnosis and treatment of personality factors in chronic low back pain. Clinical Orthopedics, 129, 141-149.

Carlsson AM. (1986). Personality characteristics of patients with chronic pain in comparison with normal controls and depressed patients. Pain, 25(3), 373-382.

Catalano \& Hardin. (1996). The Chronic Pain Control Workbook. New York: MJF Books. 
Chapman C, \& Gavris J. (1999). Suffering: the contributions of persistent pain. Lancet, $353,2233-2237$.

Cohen S \& Wills T. (1985). Stress, social support, and the buffering hypothesis. Psychological Bulletin, 98, 310-357.

Devellis BM. (1993). Depression in rheumatological distress. Baillier's Clinical Rheumatology, 7(2), 241-255.

Devellis BM (1995). The psychological impact of arthritis: prevalence of Depression. Arthritis Care and Research, 8(4), 284-289.

Doan BD \& Wadden NP. (1989) Relationships between depressive symptoms and descriptions of chronic pain. Pain, 36, 75-84.

Dworkin RH, Richlin D, Handlin D \& Brand L. (1986) Predicting treatment response in depressed and non-depressed chronic pain patients. Pain, 24, 343-353.

Dworkin RH \& Gitlin MJ. (1991) Clinical aspects of depression in chronic pain patients. Clinical Journal of Pain, 7(2), 79-94.

Dworkin RH, Harstein G, Rosner HL, Walther RR, Sweeny EW, \& Brand L. (1992). A high-risk method for studying psychosocial antecedents of chronic pain: the prospective investigaton of herpes zoster. Journal of Abnormal Psychology, 101, 200-205.

Engle GL. (1959). Psychogenic pain and the pain-prone patient. American Journal of Medicine, 26, 899-918.

Faucett J \& Levine J. (1991). The contributions of interpersonal conflict to chronic pain in the presence or absence of organic pathology. Pain, 44, 35-43.

Faucett J. (1994) Depression in painful choice disorders: the role of pain and conflict about pain. Journal of Pain Symptoms Managment, 9(8) 520-526.

Fitzpatrick R, Newman S, Archer R, \& Shipley M. (1991). Social support, disability, and depression: a longitudinal study of rheumatoid arthritis. Social Science Medicine, 33, 605-611.

Flor H, Kerns RD \& Turk DC. (1987). The role of spouse reinforcement, perceived pain, and activity levels of chronic pain patients. Journal of Psychosomatic Research, 31(2), 251-259.

Freud S. (1917). Mourning and Melanchollia. In: E. Jopnes (Ed.), Collected Papers, Vol. 4, Hogarth Press, London. 1925, pp.152-170. 
Gamsa A \& Vikis-Freibergs V. (1991). Psychological events are both risk factors in, and consequences of chronic pain. Pain, 44, 271-277.

Garro L. (1994). Narrative representations of chronic illness experience: cultural models of illness, mind, and body in stories concerning the temporomandibular joint (TMJ). Social Science Medicine, 38, 775-788.

Glanz K, Lewis FM, Rimer B. (1997). Health Behavior and Health Education $2^{\text {nd }}$ ed. San Francisco: Jossey-Buss Inc.

Goldberg G, Kerns R, \& Rosenberg R. (1993). Pain-relevant support as a bugger from depression among chronic pain patients low in instrumental activity. Clinical Journal of Pain, 9, 34-40.

Goodenow C, Seisine ST, \& Grady KE. (1990). Quality of social support and associated social and psychological functioning in women with rheumatoid arthritis. Health Psychology, 9(3), 266-284.

Haley WE, Turner JA, \& Romano JM. (1985). Depression in chronic pain patients: relation to pain, activity, and sex differences. Pain, 23(4), 337-343.

Hawley DJ \& Wolfe F. (1988). Anxiety and depression in patients with rheumatoid arthritis: a prospective study of 400 patients. Journal of Rheumatology, 15(6), 932-941.

Haythornthwaite J, Sieber W \& Kerns R. (1991). Depression and he chronic pain experience. Pain, 46, 177-184.

Helman C. (1985). Psyche, soma, and society: the social construction of psychosomatic disorders. Culture, Medicine and Psychiatry, 9, 1-26.

Henderson S, Byrne D, \& Duncan Jones P. (1981). Neurosis and the Social Environment. Academic Press, Sydney.

Hendler N. (1996). The anatomy and psychopharmacology of chronic pain. Journal of Clinical Psychiatry, 43(8), 15-20.

Jackson J. (1994). Chronic pain and the tension between the body as subject and object. In: Embodiment and experience. Cambridge: Cambridge Press.

Kantor T. (1996). Evolving trends in the management of chronic pain: Introduction. American Journal of Medicine, 101, 1A-1S.

Kerns RD \& Turk DC. (1984). Depression and chronic pain: the mediating role of the spouse. Journal of Marriage and Family, 46, 845-852. 
Kerns RD, Haythornthwaite JA, Southwick S, \& Giller EL. (1990) The role of marital interaction in chronic pain and depressive symptoms severity. Journal of Psychosomatic Research, 34, 401-408.

Kleinman A. (1988). The Illness Narratives: Suffering, Healing, and the Human Condition. US: Basic Books.

Knorring L, Perris C, Eisman M, Erickson U, \& Perris H. (1983). Pain as a symptom in depressive disorders II. Relationship to personality traits as assessed by means of KSP. Pain, 17, 377-384.

Lennon MC, Link BG, Marbach JJ, \& Dohrenwend BP. (1989). The stigma of chronic facial pain and its impact on social relationships. Social Problems, 36, 117-134.

Light AR. (1992). The Initial Processing of Pain and its Descending Control: Spinal and Trigeminal Systems. Basel, Switzerland: Karger.

Lindsay PG \& Wyckoff M. (1981). The depression-pain syndrome and its response to antidepressants. Psychosomatics, 22, 571-577.

Lister B. (1996). Dilemmas in the treatment of chronic pain. American Journal of Medicine 101(A), 25-55.

Markenson J. (1996). Mechanisms of chronic pain. American Journal of Medicine, 101(A), 6S-12S.

Martin PR \& Soon K. (1993). The relationship between perceived stress, social support and chronic headaches. Headache, 33(6), 307-314.

McCracken LM, Zayfert C, \& Gross RT. (1992). The pain anxiety symptoms scale: development and validation of a scale to measure fear of pain. Pain, 50, 67-73.

McCracken Lm, Gross RI, Sorg PJ, \& Edmands TA. (1993). Prediction of pain in patients with chronic low back pain: effects of an inaccurate prediction and pain-related anxiety. Behavior Research and Therapy, 31, 647-652.

Mersky H, Lau CL, Russel ES, Brooke RI, James M, Lappano S, Neilsen J, \& Tilsworth RH. (1987). Screening for psychiatric morbidity. The pattern of psychological illness and premorbid characteristics in four chronic pain populations. Pain, 30(2), 141-157.

Miller T \& Kraus F. (1990). An overview of chronic pain. Hospital and Community Psychiatry, 41(4), 433-440.

Murphy D, Lindsay S, \& de C Williams A. (1997). Chronic low back pain: predictions of pain and relationship to anxiety and avoidance. Behavior Research and Therapy, 35, 231-238. 
Parker JC \& Wright GE. (1995). The implications of depression for pain and disability in rheumatoid arthritis. Arthritis Care and Research, 8(4), 279-283.

Patrick D, Morgan M. \& Charlton J. (1986). Psychosocial support and change in the health status of physically disabled people. Social Science Medicine, 22, 1347-1354.

Pelz M \& Mersky H. (1982). A description of the psychological effects of chronic painful lesions. Pain, 14(3), 293-301.

Pennix B, Van Tilberg T, Deeg D, Kriegsman D, Boeke A, \& Van Eijk J. (1993). Direct and buffer effects of social support and personal coping resources on individuals with arthritis. Social Science Medicine, 4, 393-402.

Phillips HC. (1987). Avoidance behavior and its role in sustaining chronic pain. Behavior Research Therapy, 25, 273-279.

Pilowsky I, Chapman CR, \& Bonica JJ. (1977). Pain, depression, and illness behavior in a pain clinic population. Pain, 4(2), 183-192.

Reiss S. (1991). Expectancy theory of fear, anxiety, and pain. Clinical Psychology Review, 11, 141-153.

Revenson T, Schiaffino K, Majerovitz S, \& Gibofsky A. (1991). Social support as a double-edged sword: the relation of positive and problematic support to depression among rheumatoid arthritis patients. Social Science Medicine, 33(7), 807-813.

Rowat KM \& Knafl K. (1985). Living with chronic pain: the spouse's perspective. Pain, 23, 259-271.

Shinn M, Lehmann S, \& Wong N. (1984). Social interaction and social support. Journal of Social Issues, 40(4), 55-76.

Smith TW, Christensen AJ, Peck JR, \& Ward JR. (1994). Cognitive distortion, helplessness, and depressed mood in rheumatoid arthritis: a four-year longitudinal analysis. Health Psychology, 13, 213-217.

Turner R \& Noh S. (1988). Physical disability and depression: a longitudinal analysis. $J$ Health and Social Behavior, 29, 23-37.

Violon A. (1982). The process involved in becoming a chronic pain patient. In: Ray R, Tunks E (eds). Chronic pain: psychosocial factors in rehabilitation, rehabilitation medicine library. Williams \& Wilkins, Baltimore Maryland.

Violon A. (1987). Psychological determinants in chronic pain. Acta Neurochirurgica, Supplement, 38, 101-104. 
Wade J, Price D, Hamer R, Schwartz S \& Hart R. (1990). An emotional component analysis of chronic pain. Pain, 40, 303-310.

Wade J, Dougherty L, Hart R \& Cook, D. (1992). Patterns of normal personality structure among chronic pain patients. Pain, 48, 37-43.

Wade J, Dougherty L, Hart R, Rafi A, Price D (1992). A canonical correlation analysis of the influence of neuroticism and extraversion on chronic pain, suffering, and pain behavior, Pain, 51, 67-73.

Waddell G, Newton M, Henderson I, Sommerville D, \& Main CJ. (1993). A fearavoidance beliefs questionnaire (FABQ) and the role of fear-avoidance beliefs in chronic low back pain and disability. Pain, 52, 157-168.

Watson D. (1982). Neurotic tendencies among chronic pain patients: an MMPI item analysis. Pain, 14, 367-385.

Weinberger M, Hiner S, \& Tierney W. (1987). Assessing social support in elderly adults. Social Science Medicine, 25, 1049-1055.

Weisenberg M, Krendler ML, Schachat R, \& Werboff J. (1975). Pain: anxiety and attitudes in black, white, and Puerto Rican patients, Psychosomatic Medicine, 37(2) 123135.

White C, Lefort S, Amsel R, \& Jeans M. (1997) Predictors of the development of chronic pain. Research Nursing Health, 20, 309-318. 